\title{
Targeted Ion Parking for the Quantitation of Biotherapeutic Proteins: Concepts and Preliminary Data
}

\author{
J. Larry Campbell and J. C. Yves Le Blanc \\ AB SCIEX, Concord, Ontario, Canada
}

\begin{abstract}
Targeted ion parking (or TIPing) is the first quantitative application of ion/ion reactions for mass spectrometry. In TIPing, intact biotherapeutic proteins are electrosprayed as intact molecules (no digestion) and, as expected, many multiply protonated species are produced (e.g., $(\mathrm{M}+7 \mathrm{H})^{7+},(\mathrm{M}+8 \mathrm{H})^{8+}$, etc.). Several of these multiply charged species are selectively isolated using a quadrupole mass analyzer and then contained in a linear ion trap. The protein ions are then subjected to a proton-transfer reaction with a reagent anion. The ions undergo sequential charge reduction (e.g., to $(\mathrm{M}+6 \mathrm{H})^{6+}$ ) during a defined reaction period. Applying a low-amplitude waveform to the trap during this reaction time stops the ion/ion reaction at a chosen (and predicted) charge state for the protein. This funnels the analyte ions into a single channel with relatively high efficiency $(>50 \%$ of reactant ion signal is converted into product ion signal) that can be used for quantitation. In TIPing, the target protein's molecular weight and charge state distribution are the only prerequisite knowledge required. This information can be acquired experimentally or can be easily predicted based upon amino acid sequences. Preliminary data for a biotherapeutic protein, a domain antibody, were collected using TIPing coupled online with liquid chromatography (LC-TIPing). The LC-TIPing data demonstrate a linear response for samples from 10-1000 $\mathrm{ng} / \mathrm{mL}$ extracted from a complex plasma sample, demonstrating the analytical potential for TIPing. (J Am Soc Mass Spectrom 2010, 21, 2011-2022) (c) 2010 American Society for Mass Spectrometry
\end{abstract}

$\mathrm{I}$ $n$ recent years, the pharmaceutical industry has begun to expand its drug portfolios into therapeutic biological molecules, such as peptides, proteins, and oligonucleotides [1]. As these portfolios evolve, the industry's toolbox of analytical techniques must also expand [2]. Having the ability to identify and quantify these biomolecules in a timely and sensitive manner will be key to lower costs and faster development of such medicines.

Current analytical techniques experience limitations that could impede the streamlining of the biopharmaceutical discovery pipeline. For example, enzyme-linked immunosorbent assays (ELISA) [3, 4] are renowned for their sensitivity and selectivity for the quantitation of proteins. However, they also experience several disadvantages. Every new target analyte biomolecule requires the generation of new ELISA antibodies-an expensive and slow process that is disadvantageous in a drug discovery environment where many hundreds of candidate molecules are screened. In addition, the linear dynamic range of most ELISA assays are only 2 to 3 orders of magnitude [5]. Lastly, ELISA experiments may not have the ability to differentiate between slightly modified

Address reprint requests to Dr. J. L. Campbell, AB SCIEX, 71 Four Valley Drive, Concord, Ontario L4K 4V8, Canada. E-mail: larry.campbell@ sciex.com versions of the target protein, leading to inaccurate results. Such scenarios can occur because of (1) the presence of unwanted or unexpected post-translational modifications (PTMs) at or near the antibody binding site, (2) mistranslation during transcription, or (3) degradation of the protein [6-9].

Mass spectrometry (MS)-based methods have become popular in recent years for the quantitation of biomolecules, especially peptides $[10,11]$. The majority of these quantitative methods involve enzymatic digestion of the targeted protein samples, followed by liquid chromatographic separation of the resultant peptides with on-line detection by tandem mass spectrometry. In quantitative workflows, the mass spectrometry data are usually acquired in selected-reaction monitoring (or SRM) experiments [12, 13]. However, these MS-based methodologies are not without their disadvantages. First, tryptic peptides (and their ions) define segments of proteins only, not the intact protein. Hence, PTMs may not be identified if they do not occur on one of the tryptic peptides [14]. In addition, the digestion process can be a time-restricting stage of these analyses; even when streamlined for maximum production of proteotypic peptides [15], these digestions can become timeconsuming if the number of targeted proteins is diverse and changes regularly. Unfortunately, without such 
careful standardization of digestion protocols, reproducibility is detrimentally affected [16, 17].

Designing and implementing the SRM portion of peptide quantitation workflows can also be problematic. Electrosprayed peptides will be present in several multiply protonated forms and this distribution of charge states often changes as a function of protein concentration [18]. In addition, peptide ions are renowned for fragmenting into "ladder sequences" of $b$ and y ions [19], which are very useful for identifying the peptide, but serve only to dilute the signal needed for any potential SRM channel. Unfortunately, the fragmentation patterns for a given peptide can differ between instrument types [20], hindering easy transfer of SRM-based assays between different laboratories [17]. Even the collision-induced dissociation (CID) process utilized in SRM experiments can itself provide a degree of variability if multiple SRM channels are not used [21].

In recent years, alternative MS-based strategies have been explored for analyzing proteins as intact species, albeit with their own unique set of challenges. One principal hurdle is the fact that electrosprayed proteins typically form highly charged ions that crowd the limited $\mathrm{m} / \mathrm{z}$ range and challenge the resolving powers of most modern mass spectrometers. To alleviate this problem, several groups have explored reducing the spectral complexity of intact protein samples by decreasing the charge states of these ions. This can be accomplished by the addition of counter ions (acids, bases, etc.) to the ESI protein solutions [22, 23]. Alternatively, gas-phase ion/molecule reactions [24-28] or ion/plasma interactions [29-31] can be employed to remove protons from multiply protonated proteins, thereby yielding simpler mass spectra that contain fewer charge states dispersed over a broader range in $\mathrm{m} / \mathrm{z}$ space.

Another charge reduction technique for simplifying the mass spectra of intact proteins employs gas-phase ion/ion reactions [32-35]. These reactions, typically performed using quadrupole ion traps (3D or linear), serve to simplify or "decompress" the $\mathrm{m} / \mathrm{z}$ range in which a mixture of protein ions exists [36, 37]. Ion/ion proton-transfer reactions occur on very short timescales that become exponentially shorter with increasing charge of the reactant ions [38], and they are insensitive to ion structure [39]. While these ion/ion reactions are exothermic, little internal energy is imparted to the analyte molecules (i.e., no fragmentation occurs) due to rapid collisional cooling with surrounding gas ( $\sim$ mTorr $)$ of the trap [39].

Specificity can be imparted to ion/ion proton transfer reactions by exploiting fundamental properties of the analyte ions trapped in a quadrupole ion trap. This is accomplished in "ion parking" experiments [40] in which an auxiliary signal is applied to the ion trap during the proton-transfer reactions. The frequency of this signal matches the secular frequency of a reduced charge state of one of the protein ions. As the proton- transfer reaction generates ions of this particular charge state, the reaction is impeded and signal begins to accumulate at this $\mathrm{m} / \mathrm{z}$ value. Ion parking can be used to enhance proteins of interest, making them available for additional stages of MS/MS for sequencing [41].

In this work, we present a new alternative MS-based strategy for quantitating intact proteins on an LC-time scale that adds additional selectivity to the ion parking model. This approach, termed targeted ion parking (TIPing), employs precursor ion selection to isolate selected ions corresponding to expected charge states of the protein analyte; only these ions are trapped and subjected to ion parking. TIPing exhibits several beneficial qualities for protein quantitation: (1) it takes advantage of the multiple charging by isolating individual charge states, (2) it consolidates product ion signal selectively into a single product ion channel, (3) it shifts the analytical signal to a higher $\mathrm{m} / \mathrm{z}$, away from most chemical noise, and (4) it retains information on the intact protein, including molecular weight, noncovalent complexes, and PTMs. TIPing does not require enzymatic digestion of the analyte molecules, extensive instrument optimization, or even fragmentation of the analyte ions. Examples of the potential utility of TIPing experiments will be presented, including the quantitation of a biotherapeutic protein, a domain antibody [42] present in a complex plasma sample. While several qualitative analyses of intact proteins by LC-MS/MS using ion/ion reactions have been reported [43, 44], this marks the first quantitative application of ion/ ion reactions.

\section{Experimental}

\section{Materials}

Some of the proteins (myoglobin, $\beta$-casein, and exenatide), as well as the perfluoromethyldecalin (PFMD) and formic acid (FA) were obtained from SigmaAldrich (St. Louis, MO, USA) and were used as obtained. Acetonitrile was obtained from (Mallinckrodt Baker, Phillipsburg, NJ, USA), while deionized water $(18.2 \mathrm{M} \Omega$ ) was produced in-house using a MilliQ Plus (Millipore, Billerica, MA, USA). Samples containing a domain antibody were obtained from GlaxoSmithKline (King of Prussia, PA, USA). Standard solutions of the analyzed proteins were prepared to $1 \mu \mathrm{M}$ in 50:50 water/acetonitrile with $0.2 \%$ formic acid. The working solution of PFMD was prepared in neat acetonitrile to a concentration of $5 \mathrm{mg} / \mathrm{mL}$.

\section{Sample Preparation}

Protein-precipitated human plasma was prepared by mixing one volume of plasma with two volumes of acetonitrile, shaking for $5 \mathrm{~min}$, centrifuging for $15 \mathrm{~min}$ (9000 rpm), and diluting the supernatant with one volume of water. This matrix was used to prepare a stock solution of exenatide $(10 \mu \mathrm{g} / \mathrm{mL})$, as well as 
matrix solvent for serial dilutions to prepare calibration standards. The domain antibody samples were prepared by spiking the protein into $500 \mu \mathrm{L}$ of monkey plasma, then performing a cleanup using solid-phase extraction (SPE) under basic conditions with a 96-well $30 \mathrm{mg}$ Focus plate (Varian, Palo Alto, CA, USA), then eluting the proteins with $5 \%$ ammonium hydroxide in methanol. These samples were dried down and reconstituted in $75 / 25$ water/acetonitrile with $0.2 \%$ formic acid just before the LC-TIPing analysis.

\section{Liquid Chromatography}

Chromatographic separations were performed using a PE200 HPLC system (Perkin Elmer, Waltham, MA, USA) equipped with two HPLC pumps and a temperaturecontrolled autosampler. Samples in the autosampler were held at $5^{\circ} \mathrm{C}$. An Agilent SB C8 $2.1 \times 100 \mathrm{~mm}$ column (Agilent Technologies, Santa Clara, CA, USA) was used to separate the target protein from background components in the plasma. The reverse-phase elution gradient (mobile phase $\mathrm{A}: \mathrm{H}_{2} \mathrm{O} / 5 \%$ ACN $/ 0.2 \%$ formic acid; mobile phase $\mathrm{B}$ : $\mathrm{ACN} / 5 \% \mathrm{H}_{2} \mathrm{O} / 0.2 \%$ formic acid) was delivered with flow rate of $150 \mu \mathrm{L} / \mathrm{min}$. Proteins were eluted from the column using a linear gradient of $25 \%-80 \%$ B over $4 \mathrm{~min}$, followed by high organic $(95 \%$ B) for $2 \mathrm{~min}$, and a further $4 \mathrm{~min}$ of equilibration. The typical peak widths for the intact proteins examined in this study were $\sim 20 \mathrm{~s}$, with $\sim 10$ TIPing experiments recorded during this elution time. Sample injection volumes of $10 \mu \mathrm{L}$ were performed in triplicate.

\section{Mass Spectrometry}

All experiments (with one exception, vide infra) were performed using a prototype version of a 4000 QTRAP mass spectrometer [45, 46] (AB SCIEX, Concord, ON, Canada) that has been modified to generate and store both positive and negative ions for ion/ion reactions. Both reagent anions (PFMD radical anions) and protein cations were introduced into the mass spectrometer through a common orifice.

The ionization source is a modified DuoSpray Ion Source that comprises two independent methods of ion generation: an electrospray (ESI) source and an atmospheric pressure chemical ionization (APCI) source. The ESI source was operated in positive ion mode at +4800 $\mathrm{V}$ and generated cations from the peptide and protein samples. The APCI source, which was operated in negative ion mode at $-4800 \mathrm{~V}$, generated PFMD radical anions $(m / z 512)$. Each source is equipped with an independently controlled high voltage power supply (Applied Kilovolts, Worthing, UK). A syringe pump (Harvard Apparatus, Holliston, MA, USA) was used to supply PFMD solution at a flow rate of $50 \mu \mathrm{L} / \mathrm{min}$.

All data acquisition and control of the mass spectrometer, excluding the waveform generators, was performed by using MS Expo 3.11. The HPLC system was controlled using Analyst 1.5 (AB SCIEX), which was also utilized to analyze mass spectra and chromatograms. The calibration curve data were processed using MultiQuant 1.2 (AB SCIEX) using the following parameters: Gaussian smooth width-3.0 points, noise percentage$40 \%$, peak splitting factor-2 points, and a weighting of $1 / x^{2}$. The secular frequencies of the targeted charge state channels were calculated by using SxStability software developed in-house.

Full-scan mass spectra of one of the analytes (domain antibody) were obtained using a prototype quadrupole time-of-flight mass spectrometer, operated at $\sim 30,000$ resolving power and accumulation times of $150 \mathrm{~ms}$. All source and LC conditions used in both the full-scan and the TIPing analyses of the domain antibody were identical. The full-scan mass spectra were deconvoluted using BioAnalyst 1.5 software.

\section{Targeted Ion Parking Experiments}

The purpose of the TIPing experiments is to mass select precursor ions (adjacent charge states of a particular protein ion), to react these ions by proton transfer, and to stop this reaction selectively at a chosen lower charge state (higher $\mathrm{m} / \mathrm{z}$ ). To illustrate this workflow, the particular case for myoglobin will be detailed.

The TIPing experiment begins with both the positive voltage and nebulization gas of the ESI probe turned on. Two different $\mathrm{m} / \mathrm{z}$ windows $(\mathrm{m} / \mathrm{z} 1060$ and 1131) are sequentially transmitted with Q1 and stored in the linear ion trap in Q2. These windows correspond to the +16 and +15 charge states of myoglobin. Typically, at least two of these windows are established for consecutive charge states, but this number can be increased as needed using the QTRAP mass spectrometer.

Following a short cooling period of $25 \mathrm{~ms}$, the ESI voltage and nebulizing gas are pulsed off and the negative voltage and nebulizing gas of the APCI source are turned on. For $100 \mathrm{~ms}$, the proton transfer reagent, PFMD radical anions $(\mathrm{m} / \mathrm{z}$ 512) [47-49] are generated in the source by APCI, mass resolved by Q1 $(\sim 3-4$ Th window), and finally stored in Q2. The Q2 section of the mass spectrometer, which maintains a base pressure of $\sim 3$ mTorr of nitrogen, consists of a LINAC collision cell with auxiliary electrodes that provide an axial potential $[50,51]$. The LINAC function was turned off for the duration of the experiment, except during the injection of reagent anions and for the ejection of cations from Q2 after the ion/ion reactions. Both positive and negative ions are simultaneously stored in Q2 by applying auxiliary rf voltage $\left(200 \mathrm{kHz}, 650 \mathrm{~V}_{p-p}\right)$ to the two lenses, IQ2 and IQ3, that bookend Q2. These auxiliary voltages are provided by two Agilent 33120A waveform generators (Agilent Technologies), and are maintained for $\sim 150 \mathrm{~ms}$. During this time, proton-transfer reactions between the PFMD anions and the +16 and +15 myoglobin cations can occur within the Q2 linear ion trap.

Concurrent with the ion/ion reaction period, an auxiliary rf waveform, supplied by an Agilent 33120A 
waveform generator, is applied to two opposing rods in the Q2 array. The frequency of this waveform corresponds to the secular frequency of a charge-reduced form of the protein; in this particular scenario, the auxiliary waveform is $87.2 \mathrm{kHz}\left(1.25 \mathrm{~V}_{p-p}\right)$, corresponding to the +14 charge state of myoglobin $(\mathrm{m} / \mathrm{z} 1212)$. This waveform excites the $(\mathrm{M}+14 \mathrm{H})^{14+}$ myoglobin ions as they are formed as products of the ion/ion proton transfer reactions; this increases both the radial amplitude and the kinetic energy of these ions. As the radial amplitude increases, there is less overlap between the myoglobin cations and PFMD anions; as the kinetic energy of the myoglobin cations increases, the rate of the proton-transfer reaction decreases. As a result of these two phenomena, the ion/ion reaction slows dramatically at the +14 charge state to a point of inhibition, thus leading to ion parking [40].

After an additional cooling step of $15 \mathrm{~ms}$, the cations trapped within Q2 are transferred to Q3, trapped and cooled for an additional $15 \mathrm{~ms}$, then scanned out of Q3 by mass-selective axial ejection [52] at $1000 \mathrm{u} / \mathrm{s}$. For the TIPing experiments, a wide mass range $(\mathrm{m} / \mathrm{z} 1000-2000)$ was scanned; this was done to identify any multiply charged ions (from either analytes or contaminants) that were present in the samples and were subjected to PTRs. The cycle time of these experiments was between 1.5 and $2.0 \mathrm{~s}$, the bulk of which $(\sim 1 \mathrm{~s})$ was the acquisition of full-scan TIPing mass spectra (vide infra). It is important to note that the overall cycle time can be influenced by the charge states of the precursor ions; as demonstrated by McLuckey and coworkers [38]; for example, one would envision myoglobin ions with charge states higher than +15 and +16 to react faster, while much lower charge states would require longer reaction times. However, this relationship between charge state and reaction rate will be illustrated in the results of the domain antibody experiments (vide infra).

\section{Results and Discussion}

\section{TIPing Takes Advantage of Protein Ion Characteristics}

The inherent behavior of proteins and peptides when analyzed by ESI-MS/MS can generate challenges to the development of reliable quantitative assays. The main two difficulties are (1) the formation of several charge states for a single peptide/protein and (2) the dilution of product ion signal after a CID event, which generally yields thorough fragmentation of these species. TIPing overcomes these challenges by consolidating the signals of several charge states into a single charge state through the combination of proton-transfer reactions and selective reaction inhibition. In addition, these ion/ion reactions occur with greater reaction rates as the protein charge states increase [35, 38]. Also, the product ion signal in TIPing is not derived from a CID process, thereby avoiding the aforementioned issues of signal dilution.

\section{The Efficiency of Product Ion Production in TIPing}

In mass spectrometry-based quantitation experiments, the overall efficiency of the MS/MS process is a critical criterion. While MS/MS often increases the $\mathrm{S} / \mathrm{N}$ of an analytical signal and provides better specificity, it all too often reduces the precursor signal by orders of magnitude. For example, a typical CID process, especially one performed with a peptide or protein, is often less than $50 \%$ efficient (ratio of a single fragment ion's signal to the precursor ion signal) without the added step of sample derivatization [53]. When considering that most SRM channels track only a handful of these fragmentation patterns, one can determine that much more than half of the precursor ion population is essentially lost. This is especially true for peptide and protein ion fragmentation; while providing a rich array of fragment ions for the purposes of amino acid sequencing, CID of these ions severely dilutes any probable product ion channels for quantitation. While multiple fragmentation transitions can be summed post-analysis, many of these low abundance signals will suffer from poor $\mathrm{S} / \mathrm{N}$.

TIPing reveals itself as a relatively efficient process stated in terms of product ion signal detected for a given initial precursor ion signal. This efficiency is demonstrated in Figure $1 \mathrm{a}-\mathrm{d}$, which display the results of TIPing for two different proteins, myoglobin (Figure $1 \mathrm{a}$ and $\mathrm{b}$ ) and $\beta$ casein (Figure $1 \mathrm{c}$ and $\mathrm{d}$ ). The relative efficiency of the TIPing reaction was calculated as the ratio of the product ion signal (integrated peak areas) to the sum of the precursor ion signals (single integrated peak area) (eq 1):

$$
\% \text { Efficiency }_{\text {TIPing }}=\frac{\text { Product Ion Signal }}{\sum \text { Precursor Ion Signals }} \times 100 \%
$$

For myoglobin, the calculated TIPing efficiency was $61 \%$, while for $\beta$-casein, this value was $41 \%$. These values are generally much higher than typical CID efficiencies for similarly sized proteins. While it is well known that samples of $\beta$-casein protein can contain forms bearing either four or five phosphorylation sites, this particular analysis was focused on isolation and ion parking of the most intense charge states generated by $\mathrm{ESI}(+)$ of the untreated sample. Analysis of the PTMs was not the goal of this experiment; this was simply a demonstration of the efficient conversion of intact precursor ions to TIPing product ions.

\section{Analysis of Biotherapeutic Proteins Via LC-TIPing}

To demonstrate the potential of TIPing as a quantitative technique, an LC-TIPing method was developed to examine intact biotherapeutic proteins. The first feasibility study involved the analysis of a small $(\sim 4 \mathrm{kDa})$ protein (exenatide) spiked into protein-precipitated human plasma. As with the myoglobin and $\beta$-casein 

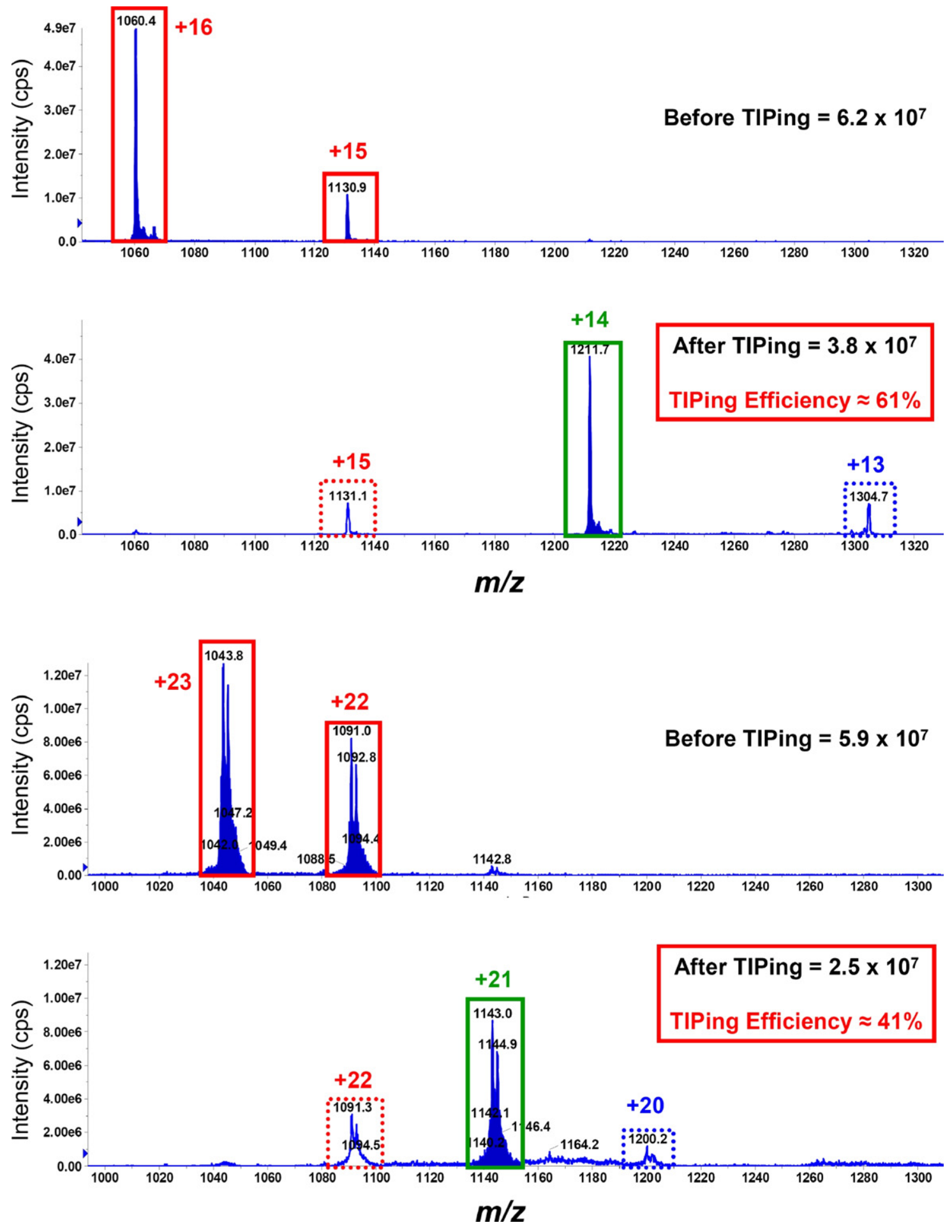

Figure 1. TIPing analysis of myoglobin (infused, from solvent); after isolation of two charge states, before (a), top spectrum and after (b), bottom spectrum, TIPing. TIPing analysis of $\beta$-casein (infused, from solvent); after isolation of two charge states, before (c), top spectrum, and after (d), bottom spectrum, TIPing. Indicated on the spectra are the two selected precursor ions (in red), the targeted analyte charge state (in green), and two charge states formed by excess charge reduction (in blue).

proteins, a solution of exenatide in solvent was subjected to ESI $(+4800 \mathrm{~V}, 50 / 50$ water/acetonitrile with $0.2 \%$ formic acid) and its most intense charge states identified ( +5 at $\mathrm{m} / \mathrm{z} 838$ and +4 at $\mathrm{m} / \mathrm{z}$ 1047) (Figure 2a). These precursor ions were subjected to TIPing using an optimized auxiliary waveform $(1000 \mathrm{mV}, 59.40$ $\mathrm{kHz}$ ) to "park" the PTR reaction products at the +3 charge state $(m / z$ 1396) (Figure $2 b)$ with good efficiency. 

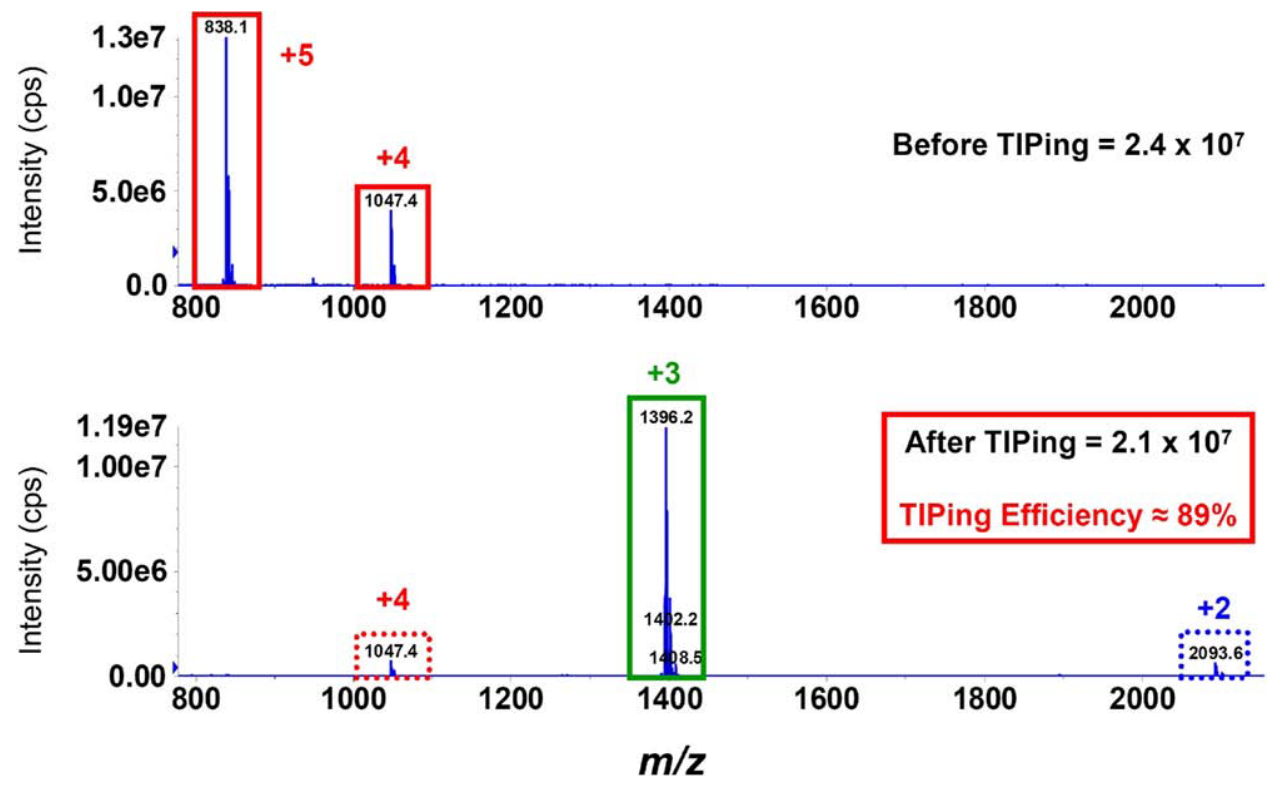

Figure 2. Analysis of exenatide (infused, from solvent); after isolation of two charge states, before (a), top spectrum and after (b), bottom spectrum, TIPing. Indicated on the spectra are the two selected precursor ions (in red), the targeted analyte charge state (in green), and two charge states formed by excess charge reduction (in blue).

With these parameters set, LC-TIPing experiments were performed; varying amounts of exenatide (spiked into protein-precipitated plasma) were injected on-column to gauge the response of the system. Figure S1, of the supplemental information (which can be found in the electronic version of this article), displays the data acquired for an injection of $200 \mathrm{pg}$ of exenatide oncolumn (5 $\mu \mathrm{L}$ of $40 \mathrm{ng} / \mathrm{mL}$ sample), including the (a) TIC, (b) XIC for the TIPing product ion, and (c) the full-scan mass spectrum acquired during the exenatide elution period. While the linear response of the LCTIPing method in the presence of some chemical noise was promising (see Figure S2, calibration curve), the protein-precipitated plasma was not as complex a matrix as one would normally encounter in these analyses. One would envision that acetonitrile protein precipitation is not an effective method for retaining biotherapeutic proteins.

With this feasibility study complete, a more challenging sample set was analyzed to tax the LC-TIPing technique. A larger protein, a domain antibody $[42,54]$, present in a more complex plasma matrix was analyzed by LC-TIPing. These proteins are the smallest component of a traditional antibody that maintain the ability to bind antigens; however, given their much simpler composition and synthesis, these domain antibodies can be more easily modified to yield specific binding interactions. The particular domain antibody protein analyzed here consists of 119 amino acids with a molecular weight of $\sim 13 \mathrm{kDa}$, and produces a series of multiply charged ions from charge state $+12(\mathrm{~m} / \mathrm{z} 1082)$ to $+7(\mathrm{~m} / \mathrm{z} 1866)$ under standard positive ESI conditions (Figure 3$)$. The two most abundant charge states $(+11$, $\mathrm{m} / \mathrm{z} 1189$ and $+10, \mathrm{~m} / \mathrm{z}$ 1307) were selected as the TIPing precursor ions (Figure 3a); the +9 charge state $(\mathrm{m} / \mathrm{z}$ 1452) was selected as the TIPing product ion (Figure $3 b)$. The TIPing auxiliary waveform $(525 \mathrm{mV}, 31.25$ $\mathrm{kHz}$ ), while optimized, still yielded some charge reduction beyond the +9 charge state. However, this occurrence is a compromise since more aggressive excitation conditions could lead to analyte fragmentation (CID) and subsequent signal loss. The TIPing experiments were optimized with a total experimental cycle time of $\sim 1.5 \mathrm{~s}$.

Figure S3 displays the measured responses in the extracted ion chromatograms for the matrix-matched blank, as well as the 50 and $1000 \mathrm{ng} / \mathrm{mL}$ standards. The analytical signal for the TIPing experiments was an extracted ion chromatogram of $\mathrm{m} / \mathrm{z}$ 1451.5-1452.5 taken from the final full-scan mass spectrum. Domain antibody protein samples ranging in concentration from 5 to $1000 \mathrm{ng} / \mathrm{mL}$ were analyzed by LC-TIPing. A linear response was obtained for samples with concentrations ranging from $10 \mathrm{ng} / \mathrm{mL}$ (LOQ) to $1000 \mathrm{ng} / \mathrm{mL}(100$ pg-10 ng of protein on-column) for the protein, with reasonable accuracies and reproducibilites (Figure 4). At the $5 \mathrm{ng} / \mathrm{mL}$-level, reproducibility of the sample fell below acceptable levels $(20 \% \mathrm{CV})$, such that $10 \mathrm{ng} / \mathrm{mL}$ is considered the LOQ for the process. Potentially, the implementation of longer cation fill times for samples with lower signal levels (concentrations) would increase the sensitivity of the LC-TIPing experiments.

It is also important to note that no internal standard (IS) was used in the LC-TIPing experiments. However, one potential IS could be a molecule that generates only singly charged ions upon ESI. Such an ion would be present in the Q2 reaction volume during the ion/ion 


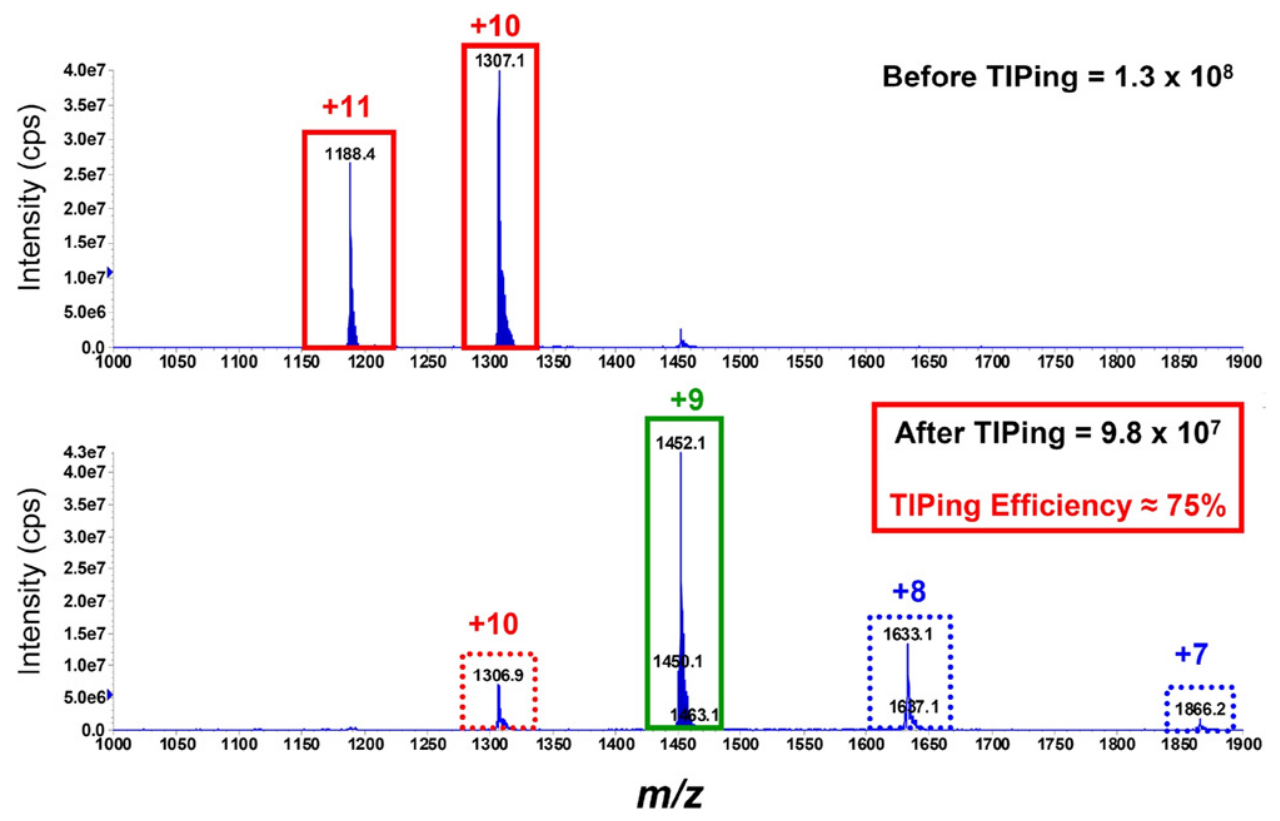

Figure 3. TIPing analysis of a domain antibody (infused, from solvent); after isolation of two charge states, before (a), top spectrum) and then after (b), bottom spectrum, TIPing. Indicated on the spectra are the two selected precursor ions (in red), the targeted analyte charge state (in green), and two charge states formed by excess charge reduction (in blue).

reaction event, but it will have a much slower ion/ion reaction rate than the more highly charged analyte [38]. Accordingly, this ion would not react over the timescale selected for the optimal reaction of the more reactive multiply charged analyte ions.

\section{How Does LC-TIPing Compare with More Traditional LC-MS/MS Analyses?}

More conventional mass spectrometric analyses have been performed on the same domain antibody protein

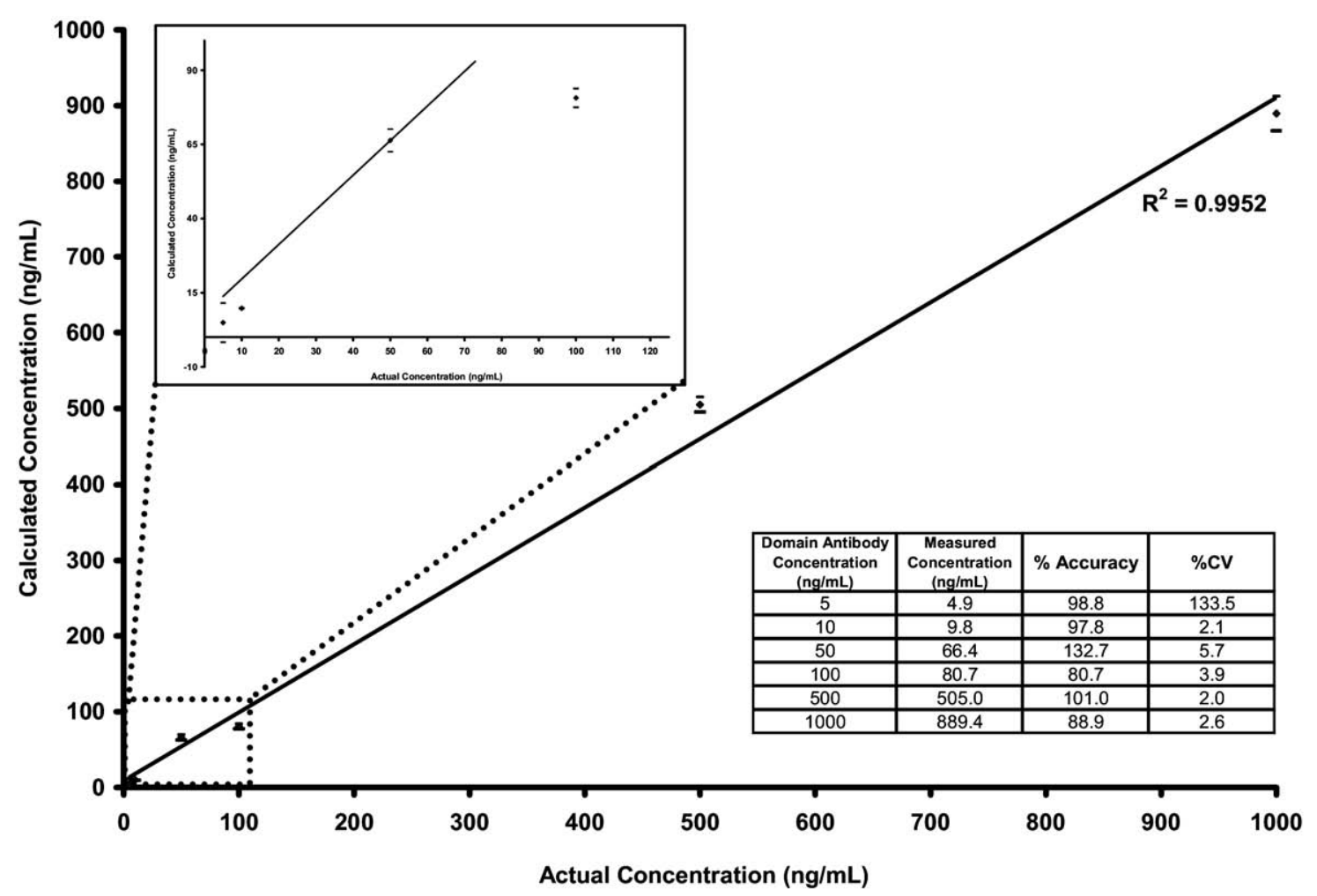

Figure 4. Calibration curve obtained during the LC-TIPing analysis of a domain antibody protein. 
using the identical sample preparation and clean-up methods, as well as a mass spectrometer of comparable sensitivity (API 4000; AB SCIEX) to the instrument employed in the present study [54]. Two different approaches were employed, both of which relied upon using SRM to provide selectivity for the analyses (precursor ion selected by Q1, CID in Q2, and product ion filtering by Q3). This first approach involved performing an SRM experiment on the intact protein, using the fragmentation transition of the intact $(\mathrm{M}+10 \mathrm{H})^{10+}$ ion $(\mathrm{m} / \mathrm{z}$ 1307) to a characteristic fragment ion of $\mathrm{m} / \mathrm{z} 193$. This method was simple to optimize, required little sample pre-treatment (see Experimental section), and could easily be modified to analyze a different protein analyte. However, this method provided an LOQ of only $50 \mathrm{ng} / \mathrm{mL}$ (linear range: $50-1000 \mathrm{ng} / \mathrm{mL}$ ), in part to the variability of the CID process on such a large target ion. It is also worth noting that the fragmentation (CID) efficiency for intact proteins can be very dependent upon the precursor ion's charge state and sequence; in this particular scenario, the most efficient fragmentation pathway was the one that was selected for the SRM.

The second methodology that was examined involved an initial tryptic digest of the domain antibody sample; this required much more exhaustive optimization of the digestion procedure, the HPLC protocol, and the selection of the SRM conditions. Ultimately, the most sensitive and selective SRM channel was identified as the fragmentation of a peptide of $m / z 794$ (a doubly charged tryptic peptide ion) to a product ion of $\mathrm{m} / \mathrm{z} 244$. With this SRM method, the authors obtained a lower LOQ of $1 \mathrm{ng} / \mathrm{mL}$ (linear range: $1-500 \mathrm{ng} / \mathrm{mL}$ ), albeit at the expense of a time-consuming optimization of the tryptic digestion process. However, the inherent variability in these digestions could still be a factor in method transfer, and will have to be re-optimized should another protein analyte enter the workflow of the lab.

Another potential technique that was considered is a single-ion monitoring (SIM) experiment, where the most abundant charge state of the domain antibody protein was mass filtered in both Q1 and Q3 without using any fragmentation or ion/ion reactions. In a SIM-type experiment, analyte signal and chemical noise are analyzed simultaneously; conversely, in the TIPing experiments, any chemical noise present in the matrix near the analyte channel (i.e., $m / z$ 1452) would not be a part of the signal since these ions were not permitted to enter the trap under the conditions established by the mass filtering Q1.

Experimental data were acquired to demonstrate why a SIM workflow would be impractical for the analysis of the domain antibody samples. An exact replica of the domain antibody calibration curve (prepared and handled exactly the same as the TIPing samples) was analyzed using a prototype quadrupoletime-of-flight mass spectrometer. Figure $\mathrm{S} 4$ displays the XICs for the three most abundant charge states of the domain antibody protein as measured in full-scan mass spectra. The width of the XICs was set to 0.7 Th (unit resolution) to mimic the resolving power of a triplequadrupole-based SIM experiment. The blue traces represent the "SIM" signal acquired during acquisition of a $100-\mathrm{ng} / \mathrm{mL}$ sample (1 $\mathrm{ng}$ on-column) while the magenta trace was acquired during analysis of a matrixmatched blank.

Clearly, each of the XIC channels is encumbered by a high degree of chemical noise, due in great part to the large number of other multiply charged species present in these samples. The sample clean-up procedure for this workflow was aimed at retaining as much of the low- to mid-molecular weight proteins in the monkey plasma samples; hence, many more species were extracted in addition to the target analyte. Therefore, a SIM analysis on any of these three charge states of the domain antibody protein would have likely yielded higher LOQs than TIPing.

\section{Taking a Step Back-What Else Appears in the TIPing Mass Spectra?}

As mentioned previously, the TIPing mass spectra were acquired as full-scan mass spectra with a broad mass range $(m / z 1000-2000)$ of product ions. Essentially, this would capture an accurate account of all of the ions that underwent or were formed from proton-transfer reactions, whose precursors were similar in $\mathrm{m} / \mathrm{z}(2-4 \mathrm{Th})$ to the domain antibody protein. For example, it was apparent that many other cations, both singly and multiply charged, were transmitted through Q1 at the domain antibody precursor $\mathrm{m} / \mathrm{z}$ values and reacted via proton-transfer reactions. The presence of such contaminant ions (as displayed in the total ion chromatogram in Figure 5a) is to be expected given the complex plasma matrix, which is replete with other small peptides, proteins, and lipids from the plasma.

During the ion/ion reaction time in Q2, any singly charged species present would react much slower than the multiply charged ions [38]; hence, their presence in the TIPing mass spectrum as unreacted precursors is expected. Conversely, the more highly charged contaminant ions are observed to undergo proton-transfer reactions and they appear in the TIPing mass spectrum as charge-reduced species at higher $m / \mathrm{z}$ values. For example, Figure $5 c$ displays the full-scan TIPing mass spectrum obtained during the elution time $(7.35 \pm 0.10$ min) of the domain antibody protein. Among the myriad of ions present is a peak at $\mathrm{m} / \mathrm{z} 1309.9$, corresponding to a multiply charged ion that both co-eluted and exhibited a very close $m / z$ value to the domain antibody protein. However, this ion did not contribute to the final TIPing analytical signal because it was charge-reduced to the ion at $\mathrm{m} / \mathrm{z} 1529.0$; the ions of $\mathrm{m} / \mathrm{z} 1309.9$ and 1529.0 correspond to the $(\mathrm{M}+7 \mathrm{H})^{7+}$ and $(\mathrm{M}+6 \mathrm{H})^{6+}$ charge states of a molecule of $\sim 9170 \mathrm{Da}$. 

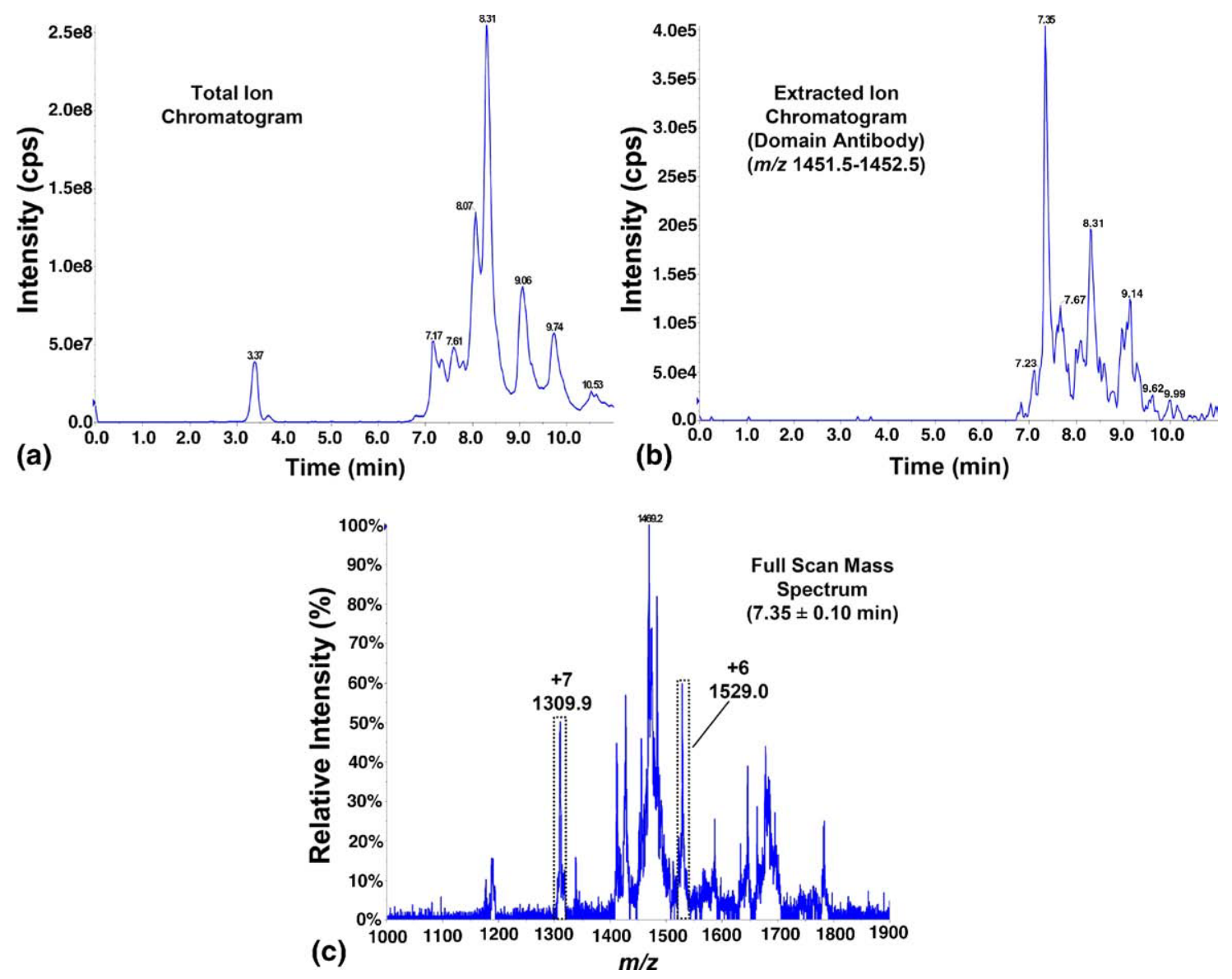

Figure 5. (a) Total ion chromatogram obtained during the LC-TIPing analysis of a domain antibody sample (10 ng/mL). (b) Extracted ion chromatogram ( $\mathrm{m} / \mathrm{z}$ 1451.5-1452.5) obtained during the same experiment as (a). (c) Full-scan mass spectrum obtained during the elution of the domain antibody protein $(7.35 \pm 0.10 \mathrm{~min})$, with the two charge states of a contaminant ion indicated.

Another interesting feature of this mass spectrum is that there is a similar number of ions at $m / z 1309.9$ and the charge-reduced $\mathrm{m} / \mathrm{z} 1529.0$ ions. This indicates that the ion/ion reaction time was insufficient to obtain full charge-reduction for these ions. Since the reaction conditions were optimized for the domain antibody protein ions, which react much faster due to their higher charge states, this is a logical conclusion. Also, since the domain antibody is selectively parked at the $\mathrm{m} / \mathrm{z}$ of the targeted charge state $(+9, m / z$ 1452), these additional contaminant ions do not interfere with the final analytical signal channel for the domain antibody (Figure 5b).

The likelihood that the contaminant ions will share both precursor ions as well as the all important TIPing product ion $\mathrm{m} / \mathrm{z}$ is quite low. To demonstrate this, we can view the relative complexity of the domain antibody samples from the perspective of a full-scan mass spectral analysis. Figure 6a displays the summed fullscan mass spectrum acquired using a prototype quadrupole time-of-flight mass spectrometer during the LC elution period of the $100 \mathrm{ng} / \mathrm{mL}$ sample of the domain antibody. Aside from the domain antibody-derived ions (highlighted in red), there is a host of other contaminant ions present in the sample, many of which are multiply charged. Again, this is to be expected in a complex plasma matrix subjected to minimal clean-up.

When this mass spectrum is deconvoluted, an interesting pattern emerges that reveals the strength of the TIPing experiments. This is encapsulated in Figure $6 \mathrm{~b}$, which displays a plot of the multiply charged ions detected as a function of their total charge, and links each of these to a deconvoluted MW (listed in the legend). Also indicated on this plot are the $\mathrm{m} / \mathrm{z}$ windows used to transmit only ions with the same $\mathrm{m} / \mathrm{z}$ values of the domain antibody precursor ions (red dashed lines at $\mathrm{m} / \mathrm{z} 1188$ and 1307), and the $\mathrm{m} / \mathrm{z}$ value used as the TIPing product ion (blue dashed line at $\mathrm{m} / \mathrm{z}$ 1452). Despite the large number of multiply charged species co-eluting with the domain antibody, none shared either of the two Q1 precursor isolation windows, meaning that none would have been included in the TIPing ion/ion reaction. However, two contaminants (MW 21,101, purple diamond and MW 23,267, purple asterisk) did display ions near the $\mathrm{m} / \mathrm{z}$ of the TIPing product ion. However, these would not have been present given the Q1 filtering of the precursor 

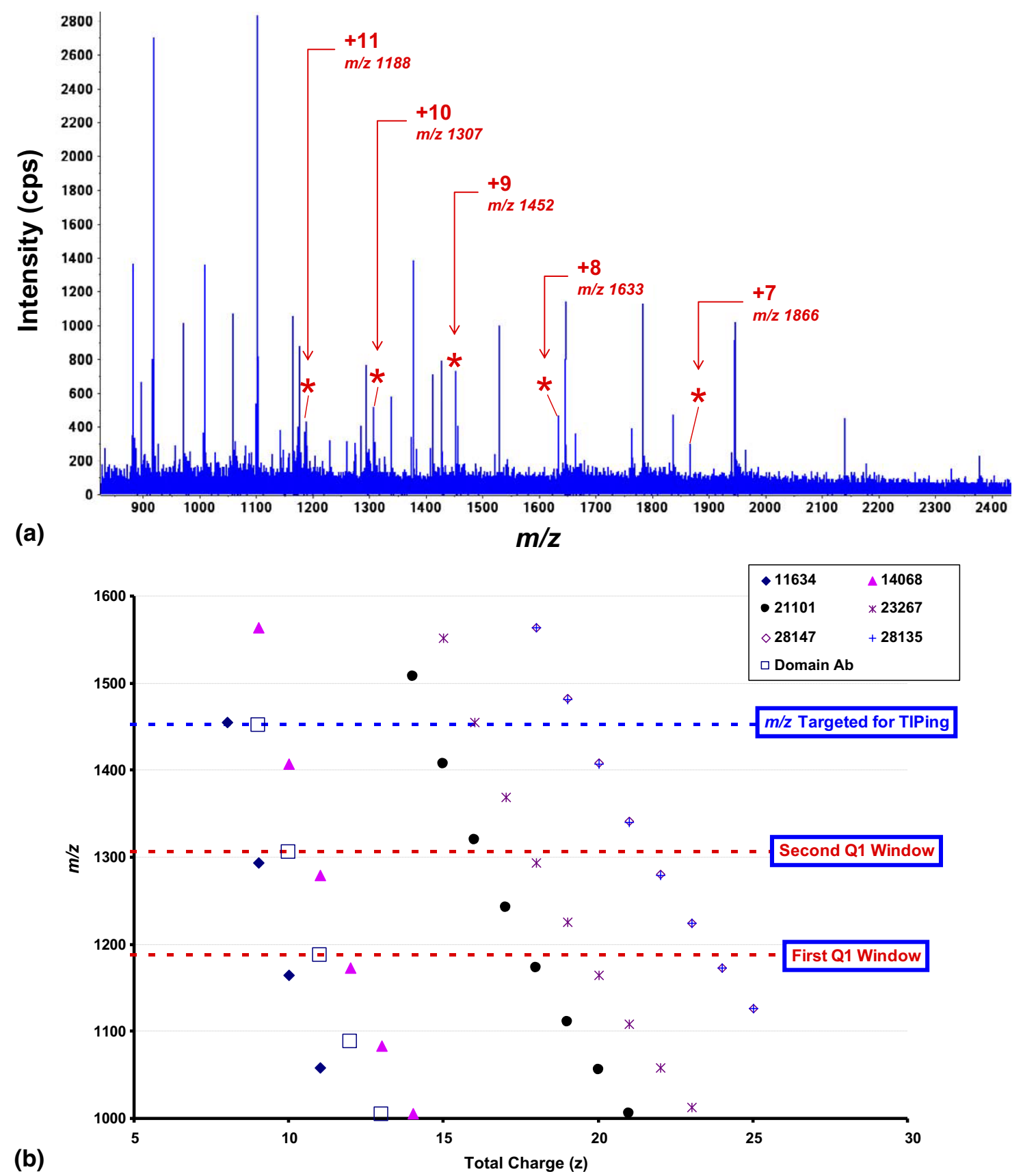

Figure 6. (a) Full-scan mass spectrum acquired using a prototype quadrupole time-of-flight mass spectrometer during the LC elution period of the $100 \mathrm{ng} / \mathrm{mL}$ sample of the domain antibody (domain antibody ions highlighted in red). (b) Plot of the multiply charged ions detected in (a), as a function of their total charge, with the deconvoluted MWs of each ion listed in the legend. Also indicated are the $\mathrm{m} / \mathrm{z}$ windows used to transmit only ions with the same $\mathrm{m} / \mathrm{z}$ values of the domain antibody precursor ions (red dashed lines at $m / z 1188$ and 1307), and the $m / z$ value used as the TIPing product ion (blue dashed line at $\mathrm{m} / \mathrm{z}$ 1452).

ions; the same is true for these contaminants' higher charged analogues.

With all of this information considered, we envision an alternative strategy for acquiring the product ion signal during TIPing experiments, which involves setting Q3 to pass only the product ions of interest (e.g., $\mathrm{m} / \mathrm{z}$ 1452) during the mass analysis step. This would result in much shorter cycle times, as well as improved sensitivity in the detection of the domain antibody proteins and will be explored in future experiments.

\section{Conclusions}

From this preliminary study, targeted ion parking (TIPing) has been shown as a promising technique for quantitat- 
ing intact biotherapeutic proteins without sample digestion and minimal knowledge (e.g., molecular weight and charge state distribution) about the analyte. With regards to efficiency, TIPing translates $>50 \%$ of precursor ion signal into product ion signal that can be used for quantitation. In the analysis of a biotherapeutic protein, a domain antibody, TIPing coupled to on-line LC separations provided reasonable analytical performance with an LOQ of $\sim 10 \mathrm{ng} / \mathrm{mL}$ in plasma.

Techniques such as TIPing could be useful in an environment where rapid turnaround of protein samples is needed, as well as analytical precision. Aside from improving the efficiency and speed of the experiments, future efforts will involve performing a more complete validation study on an LC-TIPing workflow to demonstrate the full bioanalytical viability of this approach. In addition, we will utilize TIPing to analyze oligonucleotide samples, another arena where multiply charged analytes normally pose problems.

\section{Acknowledgments}

The authors thank Drs. Chris Evans and Neil Spooner (GlaxoSmithKline) for providing the domain antibody samples, invaluable feedback, and expertise in the area of biotherapeutic proteins. The authors also thank Professor Scott McLuckey, Dr. Xiaorong Liang, and Dr. Jim Hager for helpful and insightful discussions and Dr. Frank A. Londry for invaluable assistance with both instrumentation and the SxStability software.

\section{Appendix A Supplementary Material}

Supplementary material associated with this article may be found in the online version at doi:10.1016/ j.jasms.2010.08.015.

\section{References}

1. Walsh, G. Biopharmaceuticals: Biochemistry and Biotechnology, 2nd ed.; Wiley: London, 2003.

2. Kelmsley, J. Analyzing Protein Drugs. Chem. Eng. News 2009, 87(29), 20-23.

3. Engvall, E.; Perlmann, P. Enzyme-Linked Immunosorbent Assay (ELISA). Quantitative Assay of Immunoglobulin G. Immunochemistry 1971, 8, 871-873.

4. Crowther, J. R. In ELISA: Theory and Practice; Walker, J. M., Ed.; Methods in Molecular Biology 42. Humana Press: Totowa, NJ, 1995.

5. Baker, K. N.; Rendall, M. H.; Patel, A.; Boyd, P.; Hoare, M.; Freedman, R. B.; James, D. C. Rapid Monitoring of Recombinant Protein Products: A Comparison of Current Technologies. Trends Biotechnol. 2002, 20, 149-156.

6. Clayton, A. L.; Rose, S.; Barratt, M. J.; Mahadevan, L. C. Phosphoacetylation of Histone $\mathrm{H} 3$ on c-fos- and c-jun-Associated Nucleosomes Upon Gene Activation. EMBO J. 2000, 19, 3714-3726.

7. Cheung, P. Generation and Characterization of Antibodies Directed Against Dimodified Histones, and Comments on Antibody and Epitope Recognition. Methods Enzymol. 2004, 376, 221-234.

8. Terzoglou, A. G.; Routsias, J. G.; Moutsopoulos, H. M.; Tzioufas, A. G. Post-Translational Modifications of the Major Linear Epitope 169-190aa of Ro60 kDa Autoantigen Alter the Autoantibody Binding. Clin. Exp. Immunol. 2006, 146, 60-65.

9. Srebalus Barnes, C. A.; Lim, A. Applications of Mass Spectrometry for the Structural Characterization of Recombinant Protein Pharmaceuticals. Mass Spectrom. Rev. 2007, 26, 370-388.

10. Berna, M.; Ackermann, B. Increased Throughput for Low-Abundance Protein Biomarker Verification by Liquid Chromatography/Tandem Mass Spectrometry. Anal. Chem. 2009, 81, 3950-3956.

11. Keshishian, H.; Addona, T.; Burgess, M.; Kuhn, E.; Carr, S. A. Quantitative, Multiplexed Assays for Low Abundance Proteins in Plasma by
Targeted Mass Spectrometry and Stable Isotope Dilution. Mol. Cell. Proteom. 2007, 6, 2212-2229.

12. Anderson, L.; Hunter, C. L. Quantitative Mass Spectrometric Multiple Reaction Monitoring Assays for Major Plasma Proteins. Mol. Cell. Proteom. 2006, 5, 573-588.

13. Lange, V.; Picotti, P.; Domon, B.; Aebersold, R. Selected Reaction Monitoring for Quantitative Proteomics: A tutorial. Mol. Syst. Biol. 2008, 4, 222.

14. Duncan, M. W.; Yergey, A. L.; Patterson, S. D. Quantifying Proteins by Mass Spectrometry: The Selectivity of SRM is Only Part of the Problem. Proteomics 2009, 9, 1124-1127.

15. Lesur, A.; Varesio, E.; Hopfgartner, G. Accelerated Tryptic Digestion for the Analysis of Biopharmaceutical Monoclonal Antibodies in Plasma by Liquid Chromatography with Tandem Mass Spectrometric Detection. J. Chromatogr. A 2010, 1217, 57-64.

16. Sherman, J.; McKay, M. J.; Ashman, K.; Molloy, M. P. How Specific is my SRM? The Issue of Precursor and Product Ion Redundancy. Proteomics 2009, 9, 1120-1123.

17. Addona, T. A.; Abbatiello, S. E.; Schilling, B.; Skates, S. J.; Mani, D. R.; Bunk, D. M.; Spiegelman, C. H.; Zimmerman, L. J.; Ham, A. J.; Keshishian, H.; Hall, S. C.; Allen, S.; Blackman, R. K.; Borchers, C. H.; Buck, C.; Cardasis, H. L.; Cusack, M. P.; Dodder, N. G.; Gibson, B. W.; Held, J. M.; Hiltke, T.; Jackson, A.; Johansen, E. B.; Kinsinger, C. R.; Li, J.; Mesri, M.; Neubert, T. A.; Niles, R. K.; Pulsipher, T. C.; Ransohoff, D.; Rodriguez, H.; Rudnick, P. A.; Smith, D.; Tabb, D. L.; Tegeler, T. J.; Variyath, A. M.; Vega-Montoto, L. J.; Wahlander, A.; Waldemarson, S.; Wang, M.; Whiteaker, J. R.; Zhao, L.; Anderson, N. L.; Fisher, S. J.; Liebler, D. C.; Paulovich, A. G.; Regnier, F. E.; Tempst, P.; Carr, S. A. Multi-Site Assessment of the Precision and Reproducibility of Multiple Reaction Monitoring-Based Measurements of Proteins in Plasma. Nat. Biotechnol. 2009, 27, 633-641.

18. Wang, G.; Cole, R. B. Mechanistic Interpretation of the Dependence of Charge State Distributions on Analyte Concentrations in Electrospray Ionization Mass Spectrometry. Anal. Chem. 1995, 67, 2892-2900.

19. Steen, H.; Mann, M. The abc's (and xyz's) of Peptide Sequencing. Nat. Rev. Mol. Cell. Biol. 2004, 5, 699-711.

20. Lau, K. W.; Hart, S. R.; Lynch, J. A.; Wong, S. C. C.; Hubbard, S. J.; Gaskell, S. J. Observations on the Detection of b-and y-Type Ions in the Collisionally Activated Decomposition Spectra of Protonated Peptides. Rapid Commun. Mass Spectrom. 2009, 23, 1508-1514.

21. Berna, M.; Schmalz, C.; Duffin, K.; Mitchell, P.; Chambers, M.; Ackermann, B. Online Immunoaffnity Liquid Chromatography/Tandem Mass Spectrometry Determination of a Type II Collagen Peptide Biomarker in Rat Urine: Investigation of the Impact of Collision-Induced Dissociation Fluctuation on Peptide Quantitation. Anal. Biochem. 2006, 356, 235-243.

22. Mirza, U. A.; Chait, B. T. Effects of Anions on the Positive Ion Electrospray Ionization Mass Spectra of Peptides and Proteins. Anal. Chem. 1994, 66, 2898-2904.

23. Muddiman, D. C.; Cheng, X.; Udseth, H. R.; Smith, R. D. Charge-State Reduction with Improved Signal Intensity of Oligonucleotides in Electrospray Ionization Mass Spectrometry. J. Am. Soc. Mass Spectrom. 1996, 7,697-706.

24. McLuckey, S. A.; Glish, G. L.; Van Berkel, G. J. Reactions of Dimethylamine with Multiply Charged Ions of Cytochrome c. J. Am. Chem. Soc. 1990, 112, 5668-5670

25. Hunter, A. P.; Severs, J. C.; Harris, F. M.; Games, D. E. Proton-Transfer Reactions of Mass-Selected Multiply Charged Ions. Rapid Commun. Mass Spectrom. 1994, 8, 417-422.

26. Ogorzalek-Loo, R. R.; Smith, R. D. Investigation of the Gas-Phase Structure of Electrosprayed Proteins Using Ion-Molecule Reactions. J. Am. Soc. Mass Spectrom. 1994, 5, 207-220.

27. Ogorzalek-Loo, R. R.; Smith, R. D. Proton Transfer Reactions of Multiply Charged Peptide and Protein Cations and Anions. J. Mass Spectrom. 1995, 30, 339-347.

28. McLuckey, S. A.; Goeringer, D. E. Ion/Molecule Reactions for Improved Effective Mass Resolution in Electrospray Mass Spectrometry. Anal. Chem. 1995, 67, 2493-2497.

29. Scalf, M.; Westphall, M. S.; Krause, J.; Kaufman, S. L.; Smith, L. M. Controlling Charge States of Large Ions. Science 1999, 283, 194-197.

30. Scalf, M.; Westphall, M. S.; Smith, L. M. Charge Reduction Electrospray Mass Spectrometry. Anal. Chem. 2000, 72, 52-60.

31. Ebeling, D. D.; Westphall, M. S.; Scalf, M.; Smith, L. M. Corona Discharge in Charge Reduction Electrospray Mass Spectrometry. Anal. Chem. 2000, 72, 5158-5161.

32. Ogorzalek-Loo, R. R.; Udseth, H. R.; Smith, R. D. Evidence of Charge Inversion in the Reaction of Singly Charged Anions with Multiply Charged Macro-Ions. J. Phys. Chem. 1991, 95, 6412-6415.

33. Ogorzalek-Loo, R. R.; Udseth, H. R.; Smith, R. D. A New Approach for the Study of Gas-Phase Ion-Ion Reactions Using Electrospray Ionization. J. Am. Soc. Mass Spectrom. 1992, 3, 695-705.

34. Herron, W. J.; Goeringer, D. E.; McLuckey, S. A. Product Ion Charge State Determination Via Ion/Ion Proton Transfer Reactions. Anal. Chem. 1996, 68, 257-262.

35. McLuckey, S. A.; Stephenson, J. L. Jr. Ion/Ion Chemistry of High-Mass Multiply Charged Ions. Mass Spectrom. Rev. 1998, 17, 369-407.

36. Stephenson, J. L. Jr.; McLuckey, S. A. Ion/Ion Proton Transfer Reactions for Protein Mixture Analysis. Anal. Chem. 1996, 68, 4026-4032.

37. Stephenson, J. L. Jr.; McLuckey, S. A. Charge Manipulation for Improved Mass Determination of High-Mass Species and Mixture Com- 
ponents by Electrospray Mass Spectrometry. J. Mass Spectrom. 1998, 33, 664-672.

38. McLuckey, S. A.; Stephenson, J. L. Jr.; Asano, K. G. Ion/Ion Proton Transfer Kinetics: Implications for Analysis of Ions Derived from Electrospray of Protein Mixtures. Anal. Chem. 1998, 70, 1198-1202.

39. Stephenson, J. L. Jr.; Van Berkel, G. J.; McLuckey, S. A. Ion-Ion Proton Transfer Reactions of Bio-Ions Involving Noncovalent Interactions: Holomyoglobin. J. Am. Soc. Mass Spectrom. 1997, 8, 637-644.

40. McLuckey, S. A.; Reid, G. E.; Wells, J. M. Ion Parking During Ion/Ion Reactions in Electrodynamic Ion Traps. Anal. Chem. 2002, 74, 336-346.

41. Reid, G. E.; Shang, H.; Hogan, J. M.; Lee, G. U.; McLuckey, S. A. Gas-Phase Concentration, Purification, and Identification of Whole Proteins from Complex Mixtures. J. Am. Chem. Soc. 2002, 124, 7353-7362.

42. Holt, L. J.; Herring, C.; Jespers, L. S.; Woolven, B. P.; Tomlinson, I. M. Domain Antibodies: Proteins for Therapy. Trends Biotechnol. 2003, 21, 484-490.

43. Chi, A.; Bai, D. L.; Geer, L. Y.; Shabanowitz, J.; Hunt, D. F. Analysis of Intact Proteins on a Chromatographic Time Scale by Electron Transfer Dissociation Tandem Mass Spectrometry. Int. J. Mass Spectrom. 2007, 259, 197-203.

44. Bunger, M. K.; Cargile, B. J.; Ngunjiri, A.; Bundy, J. L.; Stephenson, J. L. Jr.. Automated Proteomics of E. coli Via Top-Down Electron-Transfer Dissociation Mass Spectrometry. Anal. Chem. 2008, 80, 1459-1467.

45. Hager, J. W. Off-Resonance Excitation in a Linear Ion Trap. J. Am. Soc. Mass Spectrom. 2009, 20, 443-450

46. Campbell, J. L.; Hager, J. W.; Le Blanc, J. C. Y. On Performing Simultaneous Electron Transfer Dissociation and Collision-Induced Dissociation on Multiply Protonated Peptides in a Linear Ion Trap. J. Am. Soc. Mass Spectrom. 2009, 20, 1672-1683.
47. McLuckey, S. A.; Glish, G. L.; Asano, K. G.; Grant, B. C. Atmospheric Sampling Glow Discharge Ionization Source for the Determination of Trace Organic Compounds in Ambient Air. Anal. Chem. 1988, 60, 2220-2228.

48. McLuckey, S. A.; Wu, J.; Bundy, J. L.; Stephenson, J. L. Jr.; Hurst, G.B. Oligonucleotide Mixture Analysis Via Electrospray and Ion/Ion Reactions in a Quadrupole Ion Trap. Anal. Chem. 2002, 74, 976-984.

49. Xia, Y.; Wu, J.; McLuckey, S. A.; Londry, F. A.; Hager, J. W. Mutual Storage Mode Ion/Ion Reactions in a Hybrid Linear Ion Trap. J. Am. Soc. Mass Spectrom. 2005, 16, 71-81.

50. Thomson, B. A.; Jolliffe, C. L. Spectrometer with Axial Field. U.S. Patent 5847386, December 8, 1998.

51. Loboda, A.; Krutchinsky, A.; Loboda, O.; McNabb, J.; Spicer, V.; Ens, W.; Standing, K. G. Novel Linac II Electrode Geometry for Creating an Axial Field in a Multipole Ion Guide. Eur. J. Mass Spectrom. 2000, 6, 531-536.

52. Londry, F. A.; Hager, J. W. Mass Selective Axial Ion Ejection from a Linear Quadrupole Ion Trap. J. Am. Soc. Mass Spectrom. 2003, 14, 1130-1147.

53. Sidhu, K. S.; Sangvanich, P.; Brancia, F. L.; Sullivan, A. G.; Gaskell, S. J.; Wolkenhaue, O.; Oliver, S. G.; Hubbard, S. J. Bioinformatic Assessment of Mass Spectrometric Chemical Derivatization Techniques for Proteome Database Searching. Proteomics 2001, 1, 1368-1377.

54. Szapacs, M.; Kehler, J.; Urbanski, J.; Boram, S.; Wilson, R.; Citerone, D. The Development of a Method for the Determination of a Proprietary Domain Antibody Therapeutic Using UPLC-MS/MS. Proceedings of the 57th Annual Meeting of the American Society for Mass Spectrometry Conference on Mass Spectrometry and Allied Topics; Philadelphia, PA, June 2009. 